\title{
The Dialysis Outcomes and Practice Patterns Study (DOPPS): How Can We Improve the Care of Hemodialysis Patients?
}

\author{
David A. Goodkin, * Donna L. Mapes, ${ }^{*}$ and Philip J. Held ${ }^{\dagger}$ \\ *Amgen Inc., Thousand Oaks, California, and 'University Renal Research and Education Association, \\ Ann Arbor, Michigan
}

\begin{abstract}
Outcomes among dialysis patients vary considerably internationally and across regions within the United States. The Dialysis Outcomes and Practice Patterns Study (DOPPS) is a large, prospective, observational study of representative samples of hemodialysis patients in France, Germany, Italy, Japan, Spain, the United Kingdom, and the United States. The DOPPS collects a wealth of data regarding the patients' demographic character-

sis unit practices, and outcomes. The study seeks to clarify which dialysis practices contribute to improved mortality rates, hospitalization rates, health related quality of life, and vascular access outcomes, after adjusting for the effects of comorbid disease and demographic variables. Over 18,000 patients have been enrolled to date. This paper describes the initial findings and outlines the plans to expand the trial.
\end{abstract} istics, medical histories, laboratory values, prescriptions, dialy-
Publications during the 1990s suggested great variability in outcomes among dialysis patients. The most worrisome observations were related to mortality. The relative risk of mortality among end-stage renal disease (ESRD) patients in the United States was reported to be $15 \%$ higher than among European patients, and 33\% higher for the United States when compared with Japan (1). Due to limitations in the dialysis registry databases for these regions, these mortality rates were adjusted only for age and diabetic status. It was not possible to decipher how much of these differences in mortality were related to case mix (e.g., differing prevalences of cardiac and other disease) and how much related to varying care given to the patients. One could not determine which practices were optimal and which were potentially detrimental. Such variations in outcome were not restricted to international comparisons and were evident for other measures in addition to mortality. For example, striking differences were reported in the use of natural fistulas for vascular access across regions within the United States, unexplained by adjustment for basic demographic and comorbid disease variables (2).

Clinical researchers at Amgen Inc. decided to initiate development of a study, in partnership with key experts in the field of ESRD epidemiology, to generate new information about patient outcome differences. Philip Held was selected as principal investigator and Donna Mapes was selected as the Amgen project director. Dr. Held chairs the Steering Committee of Co-Investigators: Friedrich Port, Robert Wolfe, Eric Young, and, from Amgen, Kenneth Chen, David Goodkin, Marcia Keen, Donna

Address correspondence to: David A. Goodkin, MD, Vice President, Clinical Research, Amgen, Inc., One Amgen Center Drive, Thousand Oaks, CA 91320-1799

Seminars in Dialysis-Vol 14, No 3 (May-June) 2001 pp. 157-159
Mapes, and Bradley Maroni. The committee considered many study designs to learn which practices lead to better outcomes among dialysis patients, including randomized interventional trials. Ultimately it was decided that maximal benefit would be derived most quickly from a prospective, observational study conducted at many dialysis centers with more detailed collection of data related to patient characteristics and to specific aspects of patient care than had ever been attempted.

We planned a study of international scope to maximize the diversity of practices and patient characteristics. Multiple variables and multiple outcomes would be investigated carefully. The University Renal Research and Education Association (URREA) was designated as the international coordinating center and we established advisory boards of renal care leaders in Europe, Japan, and the United States (3). The initiative was christened the Dialysis Outcomes and Practice Patterns Study (DOPPS). The intent of the DOPPS is not to foster international comparisons in the spirit of competition or to denigrate dialysis practice in any particular region, but rather is to seek optimal approaches to treat dialysis patients around the globe.

\section{DOPPS Design}

Representative samples of hemodialysis centers were selected in the United States (161 centers), Europe (100 centers), and Japan (66 centers). The five nations with the greatest number of dialysis patients were chosen for participation in Europe: France, Germany, Italy, Spain, and the United Kingdom; Fig. 1 shows the locations of the enrolled centers. The disposition of all patients at participating centers (including mortality, transfers, and transplantation) is tracked. Random samples of individual patients within each center are studied more in- 


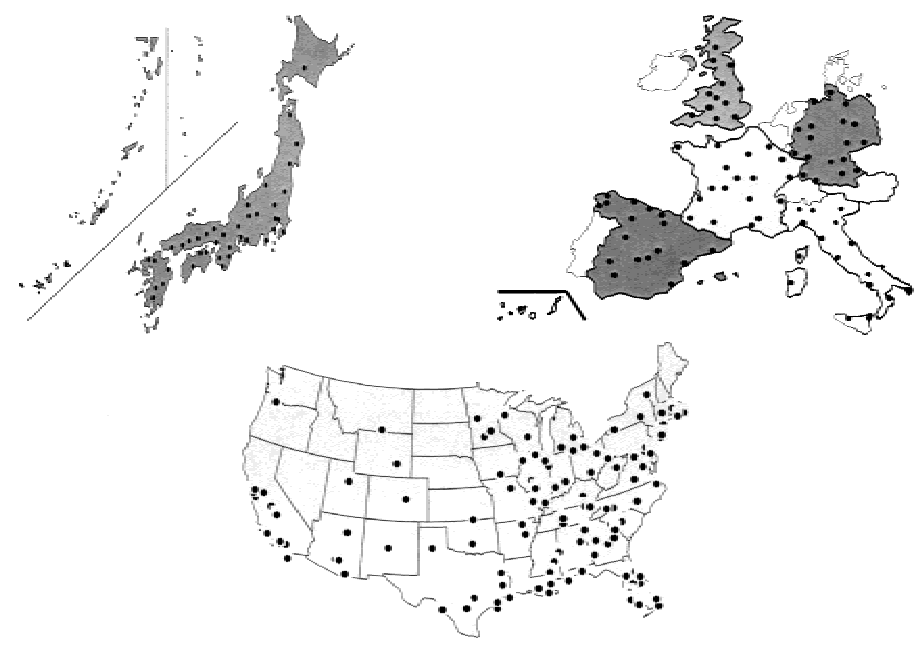

FIG. 1. International distribution of hemodialysis facilities in the DOPPS. (Facilities in Alaska and Hawaii are not shown. Each country map includes one extra dot to preserve the anonymity of the facilities.) Reprinted in modified form by permission of Blackwell Science, Inc.

tensely (e.g., they complete quality-of-life questionnaires and their laboratory data are entered into the DOPPS database). Four major categories of outcome are under study: mortality, hospitalization, vascular access, and health-related quality of life.

A wealth of data are collected regarding the patients' demographic characteristics, comorbid diseases, laboratory values, and renal history. Assessments are also made to determine details of individual patient care (e.g., prescriptions for the dialysis procedure and for medications) as well as practice patterns and characteristics at the dialysis facility level. The latter include staffing ratios for nurses and technicians, and the frequency of visits by physicians, dietitians, and social workers; patient numbers; dialyzer reuse practices; vaccination and preventive care policies; water treatment and solute concentrations; technique for assessing dialytic adequacy; and facility status (e.g., profit/not-for-profit; university or nonacademic). Separate questionnaires are completed by patients, nurse coordinators, and medical directors. All deaths, hospitalizations, and vascular access events or procedures are tracked and quality-of-life questionnaires are completed yearly. Laboratory values are updated every 4 months. A complete description of the study methods has been published (3). Patients who drop out are replaced by randomly selected patients who are new to the same unit. To date, more than 10,000 patients in the United States, 5000 patients in Europe, and 3000 patients in Japan have been enrolled.

\section{Initial Findings}

Many preliminary findings from the DOPPS have been published, predominantly in abstract form. A sample of these results is recounted here.

The demographic and comorbid disease characteristics of the hemodialysis patients were compared across the seven nations. Mean ages varied somewhat (range 58.162.2 years; U.S. 60.0 years), as did the percentages of patients who are male (range 52.9-62.0\%; U.S. 52.9\%) (3). Racial variation is much higher among U.S. hemo- dialysis patients. In the United States $52 \%$ of patients are Caucasian and $40 \%$ are African American; $84-99 \%$ of patients are Caucasian in the five European countries; $100 \%$ of the Japanese patients are listed as Asian. Coronary artery disease, congestive heart failure, hypertension, and peripheral vascular disease are significantly more prevalent in the United States than in Europe, and least prevalent in Japan (4). The prevalence of diabetes mellitus in the United States $(48.9 \%)$ is considerably higher than in Europe (21.7\%) or Japan (25.4\%). Although these conditions are significantly associated with mortality risk, the differences in comorbid disease prevalence across the continents account for only a fraction of the overall differences in mortality risk. Undoubtedly other factors remain unrecognized and practice patterns may play important roles.

Hepatitis B virus (HBV) infection is more prevalent in Japan than in Europe or the United States, and the seroconversion rate is also highest in Japan (5). Regarding practice patterns, greater risk of seroconversion is associated with a lack of an infection control policy, but not with HBV vaccination or use of isolated stations to dialyze patients with known $\mathrm{HBV}$ infection. Hepatitis $\mathrm{C}$ virus $(\mathrm{HCV})$ infection prevalence and seroconversion rate are also highest in Japan, but neither the use of infection control policies nor use of isolated dialysis stations for $\mathrm{HCV}$-positive patients could be shown to influence the risk of seroconversion (6).

The prevalence of malnutrition [moderate or severe, as measured by subjective global assessment (SGA)] among hemodialysis patients in Japan is significantly lower than in Europe or the United States, and the percentages of patients who experience decreases in serum albumin concentration, protein catabolic rate, and body mass index over 6 months of observation are also lowest in Japan (7). Lower serum albumin concentration and lower SGA predict mortality.

Renal function at the time of initiation of hemodialysis was compared between Europe and the United States. Mean estimated glomerular filtration rates among incident patients in 1998 were $8.4 \mathrm{ml} / \mathrm{min}$ in Europe and 11.1 
$\mathrm{ml} / \mathrm{min}$ in the United States; in 1999 the values were 8.6 $\mathrm{ml} / \mathrm{min}$ and $10.8 \mathrm{ml} / \mathrm{min}$, respectively (8). Thus there is no evidence to suggest that delayed initiation of dialysis in the United States explains the higher mortality rates among U.S. patients.

Initial review of vascular access data within the United States reveals the surprising finding that staff at more than $35 \%$ of the dialysis centers prefer synthetic grafts over natural fistulas (9). Unit preference significantly influences the likelihood of patients receiving a graft versus a fistula. Thus education regarding the lower thrombosis and lower infection rates for fistulas compared with grafts might change vascular access preferences and improve outcomes.

Analyses of quality-of-life data have also begun. Three summary measures from the KDQOL-SF instrument, the Physical Component Score, the Mental Component Score, and the Kidney Disease Burden all predict hospitalization and mortality in both Europe and the United States (Japanese data not yet tested) (10). The quality-of-life parameters show greater predictive power than does serum albumin concentration, one of the bestknown predictors of mortality.

\section{The Future}

Much of the DOPPS reporting to date has related to methodology and to descriptions of the characteristics of hemodialysis patients and practices internationally, because several years of observation are required to accumulate sufficient numbers of outcome events and quality-of-life questionnaires to permit endpoint evaluation. We eagerly anticipate the analyses planned for this year, which will expand on the relationships between variables related to patient demography, patient comorbidity, and dialysis practices and the critical outcomes of mortality, hospitalization, vascular access fates, and quality of life. The depth and breadth of the information collected in the DOPPS will enable the exploration of a great number of clinical questions. We hope to shed light on evidencebased best practices and improve the health and quality of life for dialysis patients. Although large, randomized, interventional studies remain the gold standard to judge the merit of specific medical practices, the number of practices impacting endpoints such as death which can be tested is limited, due to the considerable time and expense associated with these studies. The DOPPS will result in the observation of many associations between practice variables and outcomes, and may permit the inference of causation. The DOPPS will likely generate new hypotheses to improve the condition of dialysis patients.

Continuation of the DOPPS over the next few years will provide another opportunity: longitudinal monitoring of changes in practices and outcomes. In the United States, the National Kidney Foundation has issued bestpractice guidelines which are periodically updated [the Kidney Disease Outcomes and Quality Initiative (KDOQI)], and similarly the European Renal Association and the European Dialysis and Transplant Association have begun to issue the European Best Practice Guidelines in Nephrology. It should prove informative to track trends in dialysis practice to observe the extent of adoption of these recommendations and other developments. Longer periods of follow-up will also allow the study of delayed benefits of various practices and other factors. In the best of circumstances, perhaps the DOPPS will evolve into a "Framingham Study" of dialysis.

Finally, it should be noted that the DOPPS has generated enormous attention internationally. Nephrologists in many countries have expressed interest in joining the study. In 2001 we hope to expand the DOPPS to Australia, Belgium, Canada, The Netherlands, New Zealand, and Sweden, and we hope to add more nations in subsequent years.

\section{References}

1. Held PJ, Brunner F, Odaka M, Garcia JR, Port FK, Gaylin DS: Five-year survival for end-stage renal disease patients in the United States, Europe, and Japan. 1982 to 1987. Am J Kidney Dis 15:451-457, 1990

2. Hirth RA, Turenne MN, Woods JD, Young EW, Port FK, Pauly MV, Held PJ: Predictors of type of vascular access in hemodialysis patients. JAMA 276:1303-1308, 1996

3. Young EW, Goodkin DA, Mapes DL, Port FK, Keen ML, Chen K, Maroni BL, Wolfe RA, Held PJ: The Dialysis Outcomes and Practice Patterns Study (DOPPS): an international hemodialysis study. Kidney Int 57(suppl 74):S74S81, 2000

4. Akiba T, Young EW, Bommer J, Marumo F, Greenwood RN, Akizawa T, Held PJ, Goodkin DA: Prevalence of comorbidities and their effects on HD patient mortality in Europe, Japan, U.S. [abstract]. Nephrol Dial Transplant 15:A194, 2000

5. Woods JD, Kurokawa K, Combe C, Saito A, LaBrecque J, Hedderwick SA, Young EW: Hepatitis B in hemodialysis patients from three continents: the Dialysis Outcomes and Practice Patterns Study (DOPPS) [abstract]. J Am Soc Nephrol 11:306A, 2000

6. Bragg JL, Young EW, Rayner HC, Arrighi M, Greenwood RN, Akiba T, Marumo F, Wolfe RA: Hepatitis C in hemodialysis patients from three continents: the Dialysis Outcomes and Practice Patterns Study (DOPPS) [abstract]. J Am Soc Nephrol 11:258A, 2000

7. Akizawa T, Young EW, Maroni BS, Andreucci VE, Kurokawa K, Marumo F, Held PJ: Nutritional status across three continents: the Dialysis Outcomes and Practice Patterns Study (DOPPS) [abstract]. J Am Soc Nephrol 11:254A, 2000

8. Woods JD, Young EW, Goodkin D, Bragg JL, Held PJ: Renal function at initiation of hemodialysis in US \& Europe [abstract]. J Am Soc Nephrol 11:247A, 2000

9. Goodkin DA, Chen K, Held PJ, Keen MK, Mapes DL, Maroni BJ, Port FK, Wolfe RA, Young EW, Pisoni RL: Factors influencing type of permanent vascular access at start of hemodialysis. In: Proceedings of the National Kidney Foundation Clinical Nephrology Meeting. Washington, DC: 1999: 187-188

10. Mapes DL, McCullough KP, Meredith D, Locatelli F, Valderrabano F, Held PJ: Quality of life predicts mortality and hospitalization for hemodialysis (HD) patients in the U.S. \& Europe [abstract]. J Am Soc Nephrol 10:249A, 1999 